ception and design of the study and critical revision of the article and is the paper's guarantor. CL and SG analysed and interpreted the data and helped revise the article. All authors approved the final draft.

Funding: This project was supported by a grant from the University of Bologna.

Competing interests: None declared.

1 Vandenbroucke JP, van der Meer FJM, Helmerhorst FM, Rosendaal FR. Factor V Leiden: should we screen oral contraceptive users and pregnant women? BMJ 1996;313:1127-30.

2 Martinelli I, Taioli E, Bucciarelli P, Akvahan S, Mannucci PM. Interaction between the G20120A mutation of the prothrombin gene and oral con- traceptive use in deep vein thrombosis. Arterioscler Thromb Vasc Biol 1999;19:700-3

3 Frezzato M, Tosetto A, Rodeghiero F. Validated questionnaire for the identification of previous personal or familial venous thromboembolism. Am J Epidemiol 1996;143:1257-65.

4 Palareti G, Legnani C, Frascaro M, Flamigni C, Gammi L, Gola G, et al Screening of activated protein $\mathrm{C}$ resistance before oral contraceptive treatment: a pilot study. Contraception 1999;59:293-9.

5 Poort SR, Rosendaal FR, Reitsma PH, Bertina RM. A common genetic variation in the 3 '-untranslated region of the prothrombin gene is associated with elevated plasma prothrombin levels and an increase in venous thrombosis. Blood 1996;88:3698-703.

(Accepted 19 December 2000)

\title{
Gestational impaired glucose tolerance does not increase perinatal mortality in a developing country: cohort study
}

\author{
Shenaz Ramtoola, Philip Home, Hassen Damry, Anwar Husnoo, Stephen Ah-Kion
}

The high prevalence of diabetes and impaired glucose tolerance in women of childbearing age in Mauritius provides an opportunity to assess prospectively the risks of adverse outcome in pregnancy of these conditions, whether the conditions are known to be present at conception or diagnosed during pregnancy. ${ }^{1}$ The findings are likely to have consequences for healthcare planning in developing countries.

\section{Participants, methods, and results}

The study hospital (catchment population 250000 ; 4500 deliveries a year) accounts for $22 \%$ of deliveries of babies in Mauritius, hospital deliveries being $80 \%$ of all deliveries on the island. ${ }^{1}$ Cases were registered in 1993-6 at a joint obstetric and medical service for diabetes, and were also found by monitoring admissions to the obstetric wards, and by monitoring all requests for obstetric oral glucose tolerance tests. Data were collected from the mother and from hospital and national records. Diabetes and impaired glucose tolerance were diagnosed using the 1985 WHO criteria. ${ }^{2}$ Outcomes were assessed as miscarriage ( $<28$ weeks), stillbirth, live birth, or neonatal death ( $<1$ week). Neonatal data were obtained from neonatal records, and background information was obtained from national statistics and routinely collected hospital obstetric data. Standard statistical tests were used for analysis of categorical and continuous data.

A total of 294 glucose intolerant pregnancies were registered in 270 women with diabetes or impaired glucose tolerance (mean age 31; SD 6 years). Of these, 110 cases were of pregestational onset and the remainder were diagnosed during pregnancy ( 86 diabetes, 98 impaired glucose tolerance); nine were lost to follow up and 18 miscarried.

Outcome in the 267 pregnancies resulting in live birth or stillbirth is shown in the table. Perinatal
Dr A G Jeetoo Hospital, Port Louis, Mauritius Shenaz Ramtoola specialist

Hassen Damry specialist Anwar Husnoo specialist Stephen Ah-Kion specialist

Human Diabetes and Metabolism Research Centre, University of Newcastle upon Tyne NE2 4HH

Philip Home professor

Correspondence to: S Ramtoola sramtoola@ cwcom.net

Outcome of pregnancy in Mauritius, 1993-6, according to diagnostic category of glucose intolerance. Values are number (percentage) unless otherwise indicated

\begin{tabular}{|c|c|c|c|c|}
\hline & Pregestational diabetes & Gestational diabetes & $\begin{array}{l}\text { Gestational impaired } \\
\text { glucose tolerance }\end{array}$ & $\begin{array}{l}\text { Background } \\
\text { population }\end{array}$ \\
\hline Perinatal mortality per 1000 births & 124 & 116 & 22 & 26 \\
\hline Relative risk $(95 \% \mathrm{Cl})$ & 4.7 (2.7 to 8.2$)$ & $4.4(2.5$ to 7.9$)$ & $0.8(0.2$ to 3.3$)$ & \\
\hline Stillbirth per 1000 births & 67 & 81 & 11 & 14 \\
\hline Relative risk $(95 \% \mathrm{Cl})$ & $4.8(2.2$ to 10.3$)$ & 5.7 (2.8 to 11.7$)$ & $0.8(0.1$ to 5.4$)$ & \\
\hline Early neonatal mortality per 1000 live births & 60 & 38 & 11 & 12 \\
\hline Relative risk $(95 \% \mathrm{Cl})$ & $4.9(2.1$ to 11.6$)$ & $3.1(1.0$ to 9.4$)$ & $0.9(0.1$ to 6.3$)$ & \\
\hline Mean (SD) birthweight $(\mathrm{g})$ & 3059 (641) & $3293(714)$ & $3083(603)$ & $2953(567)$ \\
\hline $\mathrm{P}$ value ( $v$ background population) & NS & 0.001 & 0.05 & \\
\hline Macrosomia $(\geqslant 4000 \mathrm{~g})$ & $7(8)$ & $14(16)$ & $6(7)$ & $147(3)$ \\
\hline Relative risk $(95 \% \mathrm{Cl})$ & $2.4(1.2$ to 4.9$)$ & $4.9(3.0$ to 8.1$)$ & $2.0(0.9$ to 4.3$)$ & \\
\hline $\mathrm{P}$ value ( $v$ background population) & 0.05 & 0.001 & NS & \\
\hline Mean (SD) gestational age (weeks) & $37.0(2.4)$ & $37.7(2.3)$ & $38.5(1.8)$ & NA \\
\hline $\mathrm{P}$ value ( $\mathrm{v}$ pregestational diabetes/gestational diabetes) & NS & 0.05 & $0.001 / 0.05$ & \\
\hline Prematurity (<37 weeks) & $33(37)$ & $19(22)$ & $10(11)$ & NA \\
\hline $\mathrm{P}$ value ( $v$ pregestational diabetes/gestational diabetes) & NS & 0.05 & $0.001 / 0.05$ & \\
\hline Caesarean section & $51(58)$ & $49(57)$ & $40(43)$ & 16 \\
\hline$P$ value ( $v$ background population) & 0.001 & 0.001 & 0.001 & \\
\hline Hypoglycaemia in infant $(<1.7 \mathrm{mmol} / \mathrm{l})$ & $17(21)$ & $11(14)$ & $4(4)$ & NA \\
\hline $\mathrm{P}$ value ( $v$ gestational impaired glucose tolerance) & 0.001 & 0.05 & NS & \\
\hline Hyperbilirubinaemia in infant & $28(35)$ & $30(39)$ & $19(21)$ & NA \\
\hline $\mathrm{P}$ value ( $\mathrm{v}$ gestational impaired glucose tolerance) & 0.05 & 0.05 & NS & \\
\hline
\end{tabular}

\section{bmj.com}

This article is part of the BMJ's randomised controlled trial of open peer review. Documentation relating to the editorial decision making process is available on the BMJ's website 
mortality was $124 / 1000$ for women with pregestational diabetes and 116/1000 for women with gestational diabetes, giving relative risks well above the rate in the background population (26/1000). There was no excess perinatal mortality in women with gestational impaired glucose tolerance $(22 / 1000)$. The excess perinatal mortality in women with pregestational diabetes comprised a similar excess of stillbirths and early neonatal mortality; in gestational diabetes it was related particularly to an excess of stillbirths $(81 / 1000)$. All but one of the cases of perinatal mortality in gestational diabetes occurred in 43 women who had fasting hyperglycaemia $\geqslant 7.8 \mathrm{mmol} / \mathrm{l}$ at presentation.

Mean birth weight was significantly higher in babies born to women with gestational diabetes and impaired glucose tolerance than in the background population but not in babies born to women with pregestational diabetes (table). The incidence of macrosomia was highest in the gestational diabetes group and was also significantly increased in the pregestational diabetes group. It was not significantly increased in the group with gestational impaired glucose tolerance, despite this group having the highest gestational age at delivery. Four infants of mothers with pregestational or gestational diabetes weighed $\geqslant 4500 \mathrm{~g}(2 \%$; relative risk 9.2 (3.0 to 29.0$))$ but none weighed $\geqslant 4500 \mathrm{~g}$ in the group with gestational impaired glucose tolerance. Rates of caesarean section were significantly above background in all the glucose intolerant groups (table). Both hypoglycaemia and hyperbilirubinaemia were significantly more common in infants of women with pregestational and gestational diabetes than in those of women with gestational impaired glucose tolerance (table).

\section{Comment}

In Mauritius women diagnosed as frankly diabetic during pregnancy carry the same risks as women with pregestational diabetes, but pregnancies with gestational impaired glucose tolerance have an outcome identical to that of the background population across several measures. This is consistent with reports from Belfast and Bangkok. ${ }^{3}{ }^{4}$ The 1999 WHO Consultation reiterated that the term "gestational diabetes" should encompass both gestational impaired glucose tolerance and diabetes, and that women with impaired glucose tolerance should be managed as women with frank diabetes. ${ }^{5}$ Worldwide, most cases found on screening in pregnancy are of impaired glucose tolerance rather than diabetes. ${ }^{3}{ }^{4}$ Our data do not support using limited resources in developing countries to identify women with impaired glucose tolerance and to manage them in line with $\mathrm{WHO}$ recommendations.

Contributors: SR initiated and coordinated the study, analysed and interpreted the data, and wrote the original paper that was submitted. SR and $\mathrm{PH}$ discussed core ideas, interpretation of data, and statistical analysis. PH edited the original paper and the final version. HD and AH helped coordinate the obstetric and neonatal aspects of the study and collect obstetric and neonatal data. AH devised and introduced a standardised neonatal observation protocol for infants of diabetic mothers. SA-K participated in the day to day running of the study, including case ascertainment and data collection. SR and $\mathrm{PH}$ are the guarantors for the study.

Funding: No external funding; logistical support came from Ministry of Health of Mauritius.

Competing interests: None declared.

1 International Diabetes Institute (Australia). Mauritius Non-Communicable Disease Intervention Program. Report on 1992 disease and risk factor prevalence and incidence study. Melbourne: International Diabetes Institute, 1993.

2 WHO Study Group. Diabetes mellitus. Geneva: World Health Organization, 1985. (World Health Organization Technical Report Series 727.)

3 Roberts RN, Moohan JM, Foo RLK, Harley JMG, Traub AI, Hadden DR. Fetal outcome in mothers with impaired glucose tolerance in pregnancy. Diabet Med 1993;10:438-43.

4 Deerochanawong C, Putivanun C, Wongsuryrat M, Serirat S, Jinayon P. Comparison of National Diabetes Data Group and World Health Organization criteria for detecting gestational diabetes mellitus. Diabetologia 1996;39:1070-3

5 Alberti KGMM, Aschner P, Assal J-P, Bennett PH, Groop L, Jervell J, et al. Definition, diagnosis and classification of diabetes mellitus and its complications. Part 1:Diagnosis and classification of diabetes mellitus. Geneva: World Health Organization, 1999. (Report of a WHO Consultation.)

(Accepted 20 November 2000)

\section{A memorable patient \\ The man who had 42 psychiatrists (and rising)}

Moving on to my next post on a psychiatric training rotation some years ago I met Mr L in my first outpatient clinic. He had a huge file and had been in follow up for 20 years. As he came through the door he announced, "That drug therapy the last doctor prescribed isn't working, you know doctor." Then he sat down and, far from being jaded by the repeated re-telling, launched into a sparkling resumé of his chronic symptoms and worries. My first reaction (a little naive) was to marvel at the renewability of long-standing neurotic illness - the way it could be poured out at any time as if freshly minted.

However, my second reflection was that the institutionally minded field of psychiatry was as much the author of the shape and substance of Mr L's psychiatric career as he was. Every six months for 20 years a new registrar on rotation had listened to his ailments and tinkered with his medication, but little more. I, registrar number 41 , resolved to try to shift the paradigm away from psychiatric patienthood and its dependence on doctor legitimated inability to cope towards recovery of functioning and autonomy as an ordinary citizen. Before long he seemed to respond to this new music, and he began to mention the pills less (I wanted to phase these out) and to talk the language of social rehabilitation. Encouraged by this, when the time came for me to move on to my next post I suggested that he continue with me for sessions of reducing frequency (aiming for discharge). He agreed. He saw me twice after I moved, but then he dropped out. I don't doubt that he returned to the old set up and was taken back.

Mr L's opening salvo may be seen as putting the new doctor on his mettle. With hindsight, what might be discerned from our subsequent interactions was an impulse to keep the doctor interested and even a modest optimism that the new doctor might achieve something where a lengthening list of predecessors had failed. He picked up what I wanted to hear and for a while he gave it to me (for a while he may have also have believed some of it himself). But it is hard to give up a way of being embedded over many years, and in the end he decided that the old music, and old dance routines and partners, were better. And thus I imagine that as he came through the door to see registrar number 42 for the first time he announced, "That anti-sick role therapy the last doctor prescribed isn't working, you know doctor."

Derek Summerfield honorary senior lecturer, Department of Psychiatry, St George's Hospital Medical School, London 